\title{
Building Scientific and Technological Capacity: \\ a Role for Benefit-sharing in the Conservation and Sustainable Use of Marine Biodiversity beyond National Jurisdiction
}

\author{
Harriet R. Harden-Davies * \\ Nereus Fellow, Australian National Centre for Ocean Resources \\ and Security, University of Wollongong, New South Wales, Australia
}

Kristina M. Gjerde

Senior High Seas Advisor, IUCN Global Marine and Polar Programme and World Commission on Protected Areas, Cambridge, MA, USA

\section{Introduction}

Marine scientific research and technological innovation are crucial to investigate and conserve ocean life, capture value, and share benefits from marine genetic resources of areas beyond national jurisdiction $(\mathrm{ABNJ})$, but not all States have the required capacity. ${ }^{1}$ States have commenced negotiations for a new international legally binding instrument for the conservation and sustainable use of marine biological diversity of $\mathrm{ABNJ}$ (BBNJ agreement) ${ }^{2}$ under the 1982 United Nations Convention on the Law of the Sea (UNCLOS). ${ }^{3}$ One of the most contentious issues to overcome is how to address "marine genetic

* The authors benefited greatly from the feedback provided by three anonymous reviewers. Harriet Harden-Davies gratefully acknowledges support from the University of Wollongong, the Nereus Program and Pew Charitable Trusts.

1 UNESCO-IOc, Global Ocean Science Report: The current status of ocean science around the world, eds., L. Valdés et al., (Report, UNEsco-IOc, 2017); S.K. Juniper, "Technological, environmental, social and economic aspects," (Information Paper 3, IUCN Information Papers for the Intersessional Workshop on Marine Genetic Resources 2-3 May 2013, United Nations General Assembly Ad Hoc Open-ended Informal Working Group to study issues relating to the conservation and sustainable use of marine biological diversity beyond areas of national jurisdiction, IUCN Environmental Law Centre, 2013), 15-22.

2 United Nations General Assembly (UNGA), "International legally binding instrument under the United Nations Convention on the Law of the Sea on the conservation and sustainable use of marine biological diversity of areas beyond national jurisdiction," GA Res 72/249, 72nd sess., Agenda Item 77, UN Doc. A/Res/72/249 (24 December 2017), para. 2.

3 United Nations Convention on the Law of the Sea, 10 December 1982, 1833 United Nations Treaty Series 3 (entered into force 16 November 1994) [UNCLOS]. 
resources including questions on the sharing of benefits" through the new instrument. Debate about marine genetic resources has raged for more than a decade, ${ }^{4}$ fueled by concerns about the lack of a benefit-sharing regime applicable to marine genetic resources of $A B N J$ and evidence that just a few players are utilizing the genetic diversity of ABNJ for various applications. ${ }^{5}$ Views among States regarding the applicability, or not, of the principle of common heritage of mankind to marine genetic resources of ABNJ have been starkly divided and, so far, have proven intractable. ${ }^{6}$ Against this backdrop, the need for a "pragmatic approach" to benefit-sharing ${ }^{7}$ that links pre-existing obligations in UNCLOS with modern technologies and aspirations for equitable access 8 has emerged as a possible way to connect the common interests of all sides of the debate.

Scientific and technological capacity is a pivotal factor in accessing and using marine genetic resources from ABNJ. ${ }^{9} \mathrm{~A}$ wide range of scientific expertise and technological tools are required to access and use genetic resources, from

4 L. Glowka, "The deepest of ironies: Genetic resources, marine scientific research and the Area," Ocean Yearbook 12 (1996): 154-178.

5 R. Blasiak et al., "Corporate control and global governance of marine genetic resources," Science Advances 4, no. 6 (2018): eaar5237; S. Arnaud-Haond, J. Arrieta and C.M. Duarte, "Marine biodiversity and gene patents," Science 331 (2011): 1521-1522.

6 UNGA, "Report of the Preparatory Committee established by General Assembly Resolution 69/292: Development of an international legally binding instrument under the United Nations Convention on the Law of the Sea on the conservation and sustainable use of marine biological diversity of areas beyond national jurisdiction," UN Doc. A/AC.287/2017/PC.4/2. (31 July 2017) [PrepCom 4 report].

7 D. Tladi, "The common heritage of mankind and the proposed treaty on biodiversity in areas beyond national jurisdiction: The choice between pragmatism and sustainability," Yearbook of International Environmental Law 25, no. 1 (2015): 113-132; K. Marciniak, "Marine genetic resources: Do they form part of the common heritage of mankind principle?," in Natural Resources and the Law of the Sea: Exploration, Allocation, Exploitation of Natural Resources in Areas under National Jurisdiction and Beyond, eds., M. Lawrence, S. Constantinos and C. Hioureas (International Law Institute, 2017), 373-406.

8 A. Broggiato et al., "Mare Geneticum: Balancing governance of marine genetic resources in international waters," International Journal of Marine and Coastal Law 33, no. 1 (2018): 3-33; P. Ridings, "Redefining environmental stewardship to deliver governance frameworks for marine biodiversity beyond national jurisdiction," ICES Journal of Marine Science 75, no. 1 (2018): $435^{-443 .}$

9 S. Arico and C. Salpin, Bioprospecting of Genetic Resources in the Deep Sea-bed:Scientific, Legal and Policy Aspects (UNU IAS, 2005); A. Broggiato et al., "Fair and equitable sharing of benefits from the utilization of marine genetic resources in areas beyond national jurisdiction: Bridging the gaps between science and policy," Marine Policy 49 (2014): 176-185; M. Vierros et al., "Who owns the ocean? Policy issues surrounding marine genetic resources," Limnology and Oceanography Bulletin 25, no. 2 (2016): 29-35; P. Oldham et al., "Defra Contract MBo128, A review of current knowledge regarding marine genetic resources and their current and 
the deep and open ocean research infrastructure required to access marine genetic resources in their natural environment, to the laboratory equipment required to investigate and potentially utilize their genetic and biochemical properties. Despite the rights and responsibilities established by UNCLOS in relation to marine scientific research (Part XIII) and the development and transfer of marine technology (Part XIV), marked differences in scientific and technological capacity prevent all from accessing and utilizing marine genetic resources..$^{10}$ Consequently, it is timely to consider the potential to forge a benefitsharing solution, at least in part, that builds scientific and technological capacity and is based on the UNCLOS frameworks of Part XIII and XIV.

The objectives and guiding principles relating to marine genetic resources of $\mathrm{ABNJ}$ that are identified in the report of the Preparatory Committee (PrepCom) established by United Nations General Assembly (UnGA) Resolution 69/292 lay the foundation for such an approach and encapsulate two overarching challenges facing States in developing the вBNJ agreement. ${ }^{11}$ The first challenge concerns the aspiration for benefit-sharing to contribute to two objectives: (1) "building capacity of developing countries to access and use marine genetic resources of areas beyond national jurisdiction" and (2) "contributing to the conservation and sustainable use of marine biological diversity of areas beyond national jurisdiction."12 While this provides a clear aspiration for benefit-sharing to build capacity, the exact nature of the relationship between benefit-sharing and conservation and sustainable use has not been the subject of detailed discussion to date. The second challenge concerns the two guiding principles relating to benefit-sharing that are referred to in the PrepCom report: (1) "being beneficial to current and future generations"; and (2) "promoting marine scientific research and research and development."13 This highlights the need to strike a balance between the right to use and the responsibility to share, reflecting the presumed dichotomy between freedom of the high seas and the common heritage of mankind. Innovative solutions are

projected economic value to the UK economy," Final Report Version One, Valuing the Deep: Marine Genetic Resources in Areas Beyond National Jurisdiction (One World Analytics, 2014).

10 C. Salpin, V. Onwuasoanya, M. Bourrel and A. Swaddling, "Marine scientific research in Pacific Small Island Developing States," Marine Policy (2016), <https://doi.org/10.1016/j .marpol.2016.07.019>; G. Holland and D. Pugh, eds., Troubled Waters: Ocean Science and Governance (Cambridge University Press, 2010), p. 3.

11 UNGA, n. 2 above.

12 PrepCom 4 report, n. 6 above, para. 3.2.2(i).

13 Id., para. 3.2.2(ii). 
urgently needed to strike a balance between these two principles and translate the aspirational objectives into tangible outcomes.

This article examines whether building scientific and technological capacity could serve as a unifying focus for addressing the benefit-sharing question in a way that achieves both objectives and upholds both principles identified in the PrepCom report. First, concerning the objectives, the relationship between benefit-sharing and conservation and sustainable use of biodiversity is considered and the role of scientific and technological capacity-building is discussed. We demonstrate that there is a precedent for benefit-sharing to promote scientific and technological capacity-building, drawing examples from the 2001 International Treaty on Plant Genetic Resources for Food and Agriculture (ITPGRFA), ${ }^{14}$ the 2010 Nagoya Protocol on Access to Genetic Resources and the Fair and Equitable Sharing of Benefits Arising from Their Utilization to the Convention on Biological Diversity (Nagoya Protocol), ${ }^{15}$ the 1992 Convention on Biological Diversity (CBD), ${ }^{16}$ the Pandemic Influenza Preparedness Framework (PIP Framework), and the Global Plan of Action for Conservation, Sustainable Use and Development of Forest Genetic Resources (Forest Genetic Resources Plan). ${ }^{17}$ Second, concerning the two principles, we examine the existing legal basis for scientific and technological capacity-building in UNCLOS, considering its Parts XI, XII, XIII, and XIV. We suggest that such an approach to benefit-sharing is consistent with existing rights and responsibilities under UNCLOS. Third, we identify measures that could be included in a ввNJ agreement to specify, scale-up, and strengthen the implementation of existing UNCLOS requirements. By giving greater effect to the duty to cooperate in scientific research and the development and transfer of technology, it is suggested that these measures could support the conservation and sustainable use of biodiversity and contribute to inter- and intra-generational equity by building capacity. Additionally, we suggest that these measures would also help to build an enabling environment in which marine scientific research can flourish and

14 International Treaty on Plant Genetic Resources for Food and Agriculture, 3 November 2001, 2400 United Nations Treaty Series 303 (entered into force 29 June 2004) [ITPG RFA].

15 Nagoya Protocol on Access to Genetic Resources and the Fair and Equitable Sharing of Benefits Arising from Their Utilization to the Convention on Biological Diversity, 29 October 2010, entered into force 12 October 2014.

16 Convention on Biological Diversity, 5 June 1992, 176o United Nations Treaty Series 79 (entered into force 29 December 1993) [СвD].

17 Food and Agriculture Organization of the United Nations (FAO) Commission on Genetic Resources for Food and Agriculture, "Global Plan of Action for the Conservation, Sustainable Use and Development of Forest Genetic Resources” (2014), available online: <http:// www.fao.org/3/a-i3849e.pdf >, foreword, para. 1 [Forest Genetic Resources Plan]. 
serve as a common interest to build global capacity to conserve and capture value from the genetic diversity of marine life in $A B N J$.

\section{Benefit-Sharing: Conservation and Capacity-Building}

This section considers the two objectives for benefit-sharing identified by the PrepCom report. First, the connection between benefit-sharing and the conservation and sustainable use of biodiversity is explored by considering the nature of marine genetic resources and the link with biodiversity. Second, the importance of capacity-building as a form of benefit-sharing is examined by considering international legal instruments relating to genetic resources. The significance of international scientific cooperation and the development and transfer of technology is revealed.

\section{Conservation}

To consider the potential role of benefit-sharing in the conservation and sustainable use of в ВNJ, it is necessary to first consider the nature of genetic resources and their connection with biodiversity. Though neither mentioned nor defined in UNCLOS, genetic resources are widely considered to be "genetic material of actual or potential value," as defined in Article 2 of the СвD. Various possible interpretations of the value of genetic material, however, confront attempts to put provisions associated with this definition into practice, as it does not wholly capture the many values, biological functions, and uses of genetic resources. ${ }^{18}$ In the CBD, for example, value is identified as "ecological, social, economic, scientific, educational, cultural, recreational and aesthetic."19 Indeed, genetic resources are broadly defined as genetic material of "actual or potential economic, environmental, scientific or societal value" in the Forest Genetic Resources Plan. ${ }^{20}$ The "intrinsic value" of biodiversity is recognized in the $\mathrm{CBD}$, which makes particular reference to the social, scientific, cultural, and economic importance of genomes, genes, ecosystems, habitats, species, and communities. The importance of genetic resources to "food security, public health, biodiversity conservation, and the mitigation of and adaptation to climate change" 21 is noted in the Preamble to the Nagoya Protocol. ${ }^{22}$ However,

18 A. Deplazes-Zemp, “Genetic resources' an analysis of a multifaceted concept," Biological Conservation 222 (2018): 86-94.

19 СвD, n. 16 above, preamble, para. 1; see also CвD, id., art. 7(a) and Annex I.

20 Forest Genetic Resources Plan, n. 17 above, para. 1.

21 Nagoya Protocol, n. 15 above, preamble, para. 14.

22 Id., preamble, para. 6. 
the Nagoya Protocol only makes explicit reference to the "economic value of ecosystems and biodiversity."23 In considering the benefits to be shared under a вв NJ agreement, it will be critical to recall that the value of genetic material is ecological, environmental, scientific, societal, and more - not only economic.

That the value of genetic resources "resides in ecosystems and biodiversity" is recognized in the Preamble to the Nagoya Protocol. Indeed, genetic variability drives the diversity within and between species that creates the ecological complexes that underpin healthy ecosystems. The notion that genetic resources are part of biological resources is explicit in СвD Article 2. In the Forest Genetic Resources Plan, highlighting that genetic resources are crucial to the adaptation of ecosystems, genetic diversity is referred to as the "mainstay of biological stability."24 Marine genetic resources could be said to play an equally important role in ocean ecosystems, and are considered as ecosystem services and a necessary part of evolutionary capacity. ${ }^{25}$

Elaborating the link between benefit-sharing and the conservation and sustainable of biodiversity that is enshrined in the CBD, the Nagoya Protocol aims to "create incentives to conserve and sustainably use biological diversity." With so many marine species yet to be discovered in the 60 percent of the ocean that lies in $\mathrm{ABNJ},{ }^{26}$ in the face of growing threats to marine biodiversity, ${ }^{27}$ it is logical that benefit-sharing should be pursued with an aim to incentivize and enable the conservation and sustainable use of biodiversity in which the value of genetic resources resides.

Science and technology are crucial to understand, preserve, and capture this value as benefits. However, some see benefit-sharing, and the access measures that accompany it under most legal instruments associated with genetic resources, as a possible distraction from conservation or a hindrance to the

23 Id.

24 Forest Genetic Resources Plan, n. 17 above, foreword, para. 1.

25 C.W. Armstrong et al., "Services from the deep: Steps towards valuation of deep sea goods and services," Ecosystem Services 2 (2012): 2; A.D. Rogers et al., The High Seas and Us: Understanding the Value of High Seas Ecosystems (Global Ocean Commission, 2014); A.R. Thurber et al., "Ecosystem function and services provided by the deep sea," Biogeosciences 11, no. 14 (2014): 3941-3963.

26 J.H. Ausubel, D.T. Crist and P.E. Waggoner, eds., First Census of Marine Life 2010: Highlights of a Decade of Discovery (Census of Marine Life, 2010); E. Ramirez-Llodra et al., "Deep, diverse and definitely different: Unique attributes of the world's largest ecosystem," Biogeosciences 7, no. 9 (2010): 2851-2899; P. Snelgrove, "An ocean of discovery: Biodiversity beyond the Census of Marine Life," Planta Med 82 (o9/10) (2016): 790-799.

27 A. Merrie et al., "An ocean of surprises: Trends in human use, unexpected dynamics and governance challenges in areas beyond national jurisdiction," Global Environmental Change 27 (2014): 19-31. 
scientific research and technological innovation that is needed to support conservation. ${ }^{28}$ It is therefore important to understand the role of science and technology in acquiring and sharing benefits from genetic resources to forge workable solutions to benefit-sharing.

\section{Capacity-building: the Role of Science and Technology}

To examine the role of capacity-building as a form of benefit-sharing, it is instructive to consider existing international legal instruments relating to genetic resources. Existing legal instruments relating to genetic resources offer guidance in identifying what benefits could be derived from marine genetic resources of ABNJ; all highlight a prominent role for building capacity in science and technology. ${ }^{29}$ For example, the importance of technology transfer and cooperation to build research and innovation capacities for adding value to genetic resources, including for poverty eradication and environmental sustainability, is recognized in the Nagoya Protocol. ${ }^{30}$ In addition to "monetary" benefits, the Nagoya Protocol refers to 17 "non-monetary" benefits that can be broadly summarized as: i) collaboration and international cooperation in scientific research; ii) access to samples, data, and knowledge, including the publication and sharing of scientific knowledge; iii) capacity-building and technology transfer, including scientific training and access to resources, research infrastructure, and technology; and iv) scientific, social, and economic outcomes of research involving genetic resources, including activities for the conservation and sustainable use of biodiversity (Table 14.1). ${ }^{31}$

Although the IT PGRFA Treaty does not refer to "monetary and non-monetary benefits" or provide an indicativelist of benefits, it offers a framework for benefitsharing that is centered on scientific research and capacity-building for conservation; it broadly aligns with the categories of benefits considered under the Nagoya Protocol - albeit packaged in a different way. Article 13.2 of the ITPGRFA identifies four forms of benefit-sharing for the objective of the conservation and sustainable use of genetic resources: a) exchange of

28 D. Neumann et al., "Global biodiversity research tied up by juridical interpretations of access and benefit-sharing," Organisms Diversity and Evolution 18, no. 1 (2018), doi:10.1007/ s13127-017-0347-1.

29 See also E. Morgera, "Fair and equitable benefit-sharing at the cross-roads of the human right to science and international biodiversity law," Laws 4, no. 4 (2015): 803-831.

$30 \quad$ Nagoya Protocol, n. 15 above, art. 22 and preamble, paras. 5 and 7 .

31 This terminology originates from the 2002 Bonn Guidelines on Access to Genetic Resources and Fair and Equitable Sharing of the Benefits Arising out of Their Utilization, adopted at the Sixth Meeting of the Conference of Parties to the Convention on Biological Diversity, 7-19 April 202, Decision vi/24. 


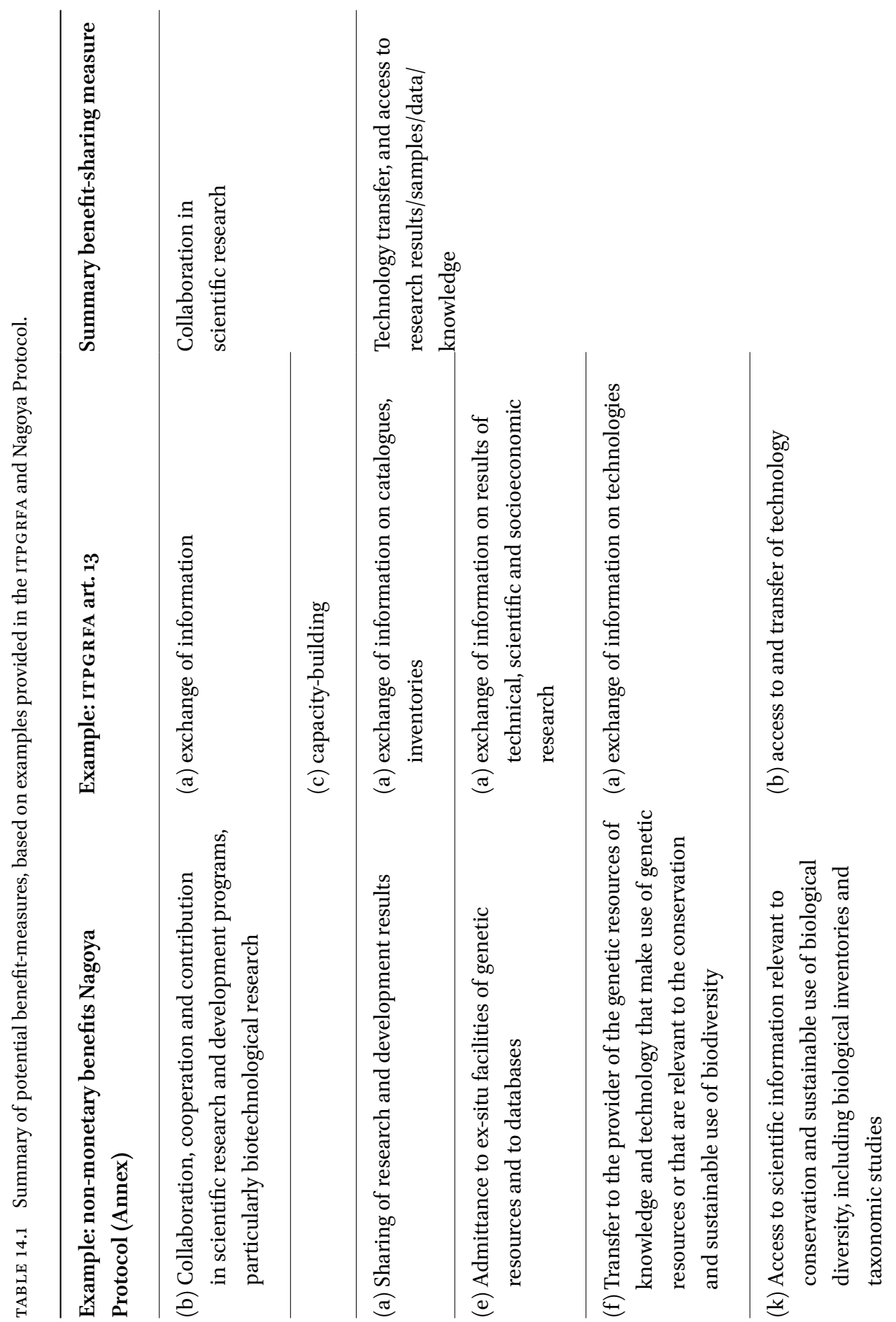




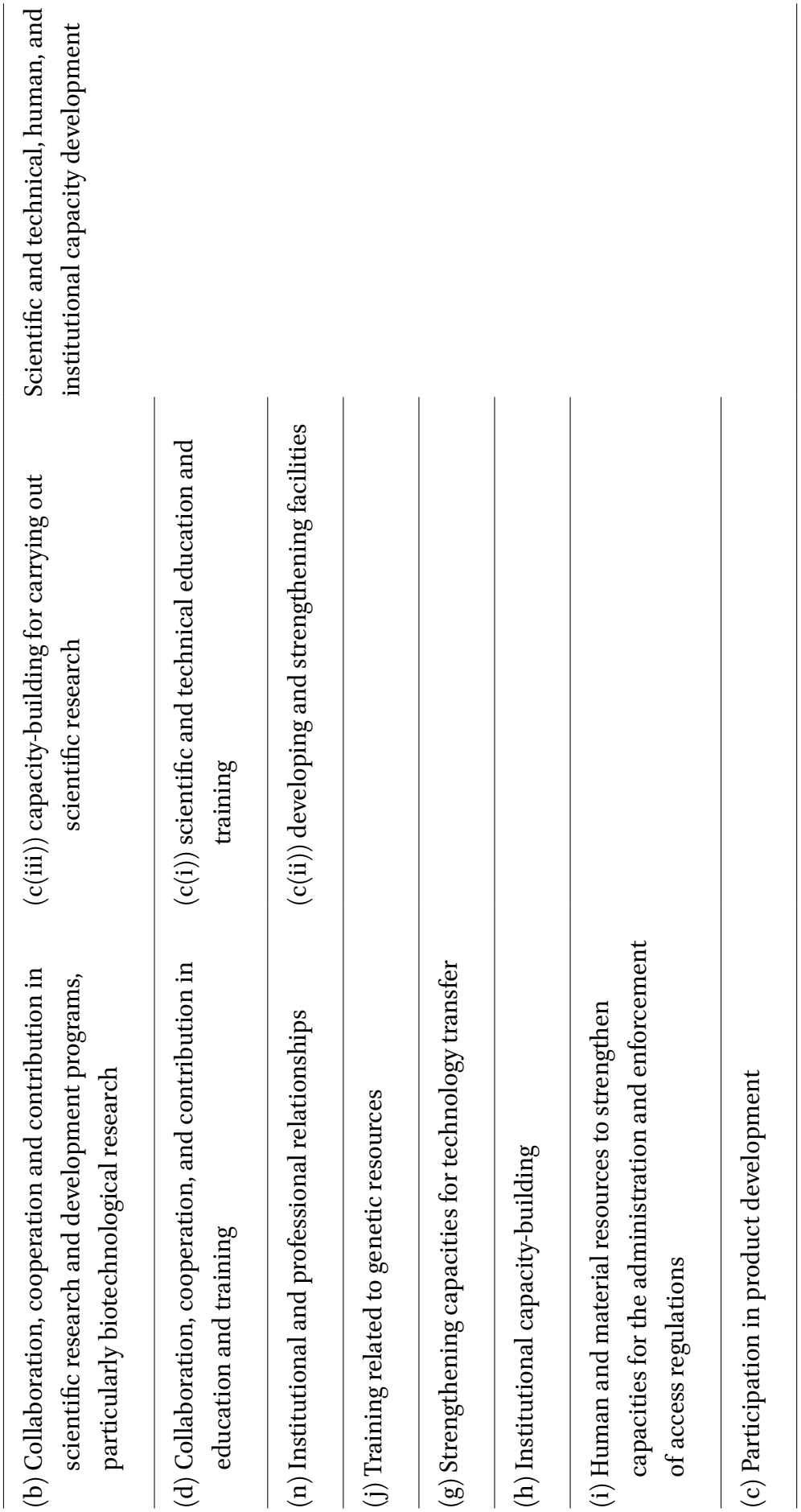




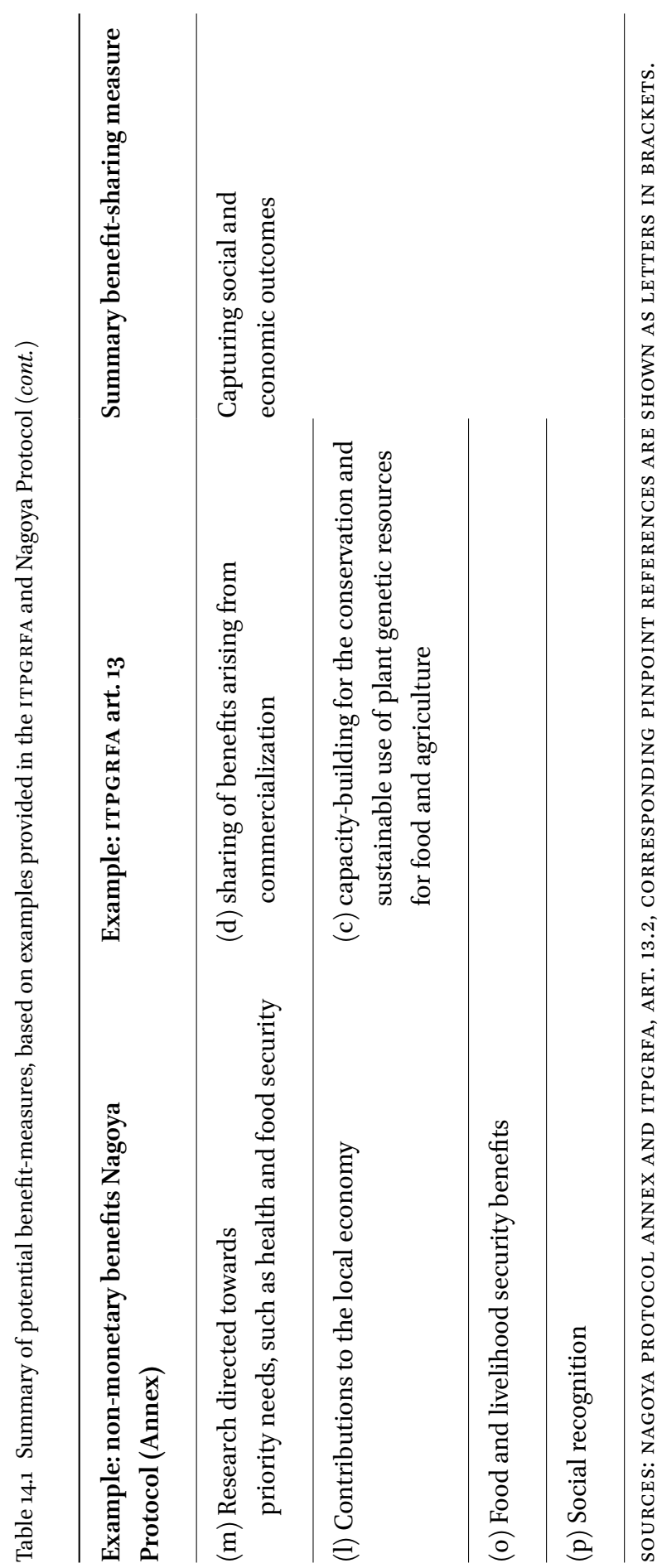


information; b) access to and transfer of technology; c) capacity-building; and d) sharing of benefits arising from commercialization. A strong emphasis on an integrated approach to benefit-sharing, based largely on international cooperation for the investigation and conservation of genetic resources, is enshrined in Articles 5 and 7 of the ITPGRFA, while Article 12 specifically recognizes that access to genetic resources is a benefit. ${ }^{32}$ Considering the benefits identified by the Nagoya Protocol and ITPGRFA (Table 14.1) reveals that benefit-sharing includes

- collaboration in scientific research;

- technology transfer, including equipment, but also access to research outcomes (such as results, samples and data), knowledge, and training opportunities; and

- capacity-building, including scientific and technical forms of capacitybuilding at human and institutional levels and at national, regional, and global scales.

That these legal instruments enshrine scientific research, technology transfer, and capacity-building as central pillars for benefit-sharing is logical, given the critical role of science and technology to derive and share benefits from genetic resources - from advancing knowledge of biodiversity, to isolating novel natural products for potential biotechnology development. Marine scientific research is widely considered to be the first step in accessing marine genetic resources in ABNJ in-situ. ${ }^{33}$ There are often dual uses and spill-over benefits possible from technology - for example, the application of genetics and genomics technologies could on the one hand be a powerful tool to understand ocean health and inform conservation measures, and could, on the other hand, be used in biotechnology development (which may or may not result in a commercial product). ${ }^{34}$ Scientific knowledge can be considered as a benefit from genetic resources. ${ }^{35}$ Indeed, advances in taxonomic and ecological knowledge arising from research involving collections, compound libraries, and research

32 H. Harden-Davies, "Research for regions: Strengthening marine technology transfer for Pacific Island Countries and biodiversity beyond national jurisdiction," International Journal of Marine and Coastal Law 32, no. 4 (2017): 797-822.

33 Oldham et al., n. 9 above.

34 A. Martins et al., "Marketed marine natural products in the pharmaceutical and cosmeceutical industries: Tips for success," Marine Drugs 12 (2014) 1066; D. Skropeta, "Exploring marine resources for new pharmaceutical applications," in Marine Resources Management, eds., W. Gullett, C. Schofield and J. Vince (LexisNexis Butterworths, 2011), 211.

35 Deplazes-Zemp, n, 18 above; M. Böhm and B. Collen, "Toward equality of biodiversity knowledge through technology transfer," Conservation Biology 29(5) (2015): 1290-1302. 
infrastructure associated with genetic resources constitute benefits that can be of "equal, or greater, importance to the potential monetary benefits from royalties should a product be commercialized."36 Access to scientific knowledge is not only a form of benefit-sharing, but also of technology transfer. ${ }^{37}$

Several further synergies between the benefits from genetic resources and technology transfer are evident when comparing definitions of benefits with the definition of marine technology as provided by the Intergovernmental Oceanographic Commission (IOC) Criteria and Guidelines on the Transfer of Marine Technology (IOC CGTMT), which includes information and data; expertise, knowledge, and skills; equipment for sampling or observations in-situ; laboratory equipment and computer software; and manuals, guidelines, standards, and reference materials. As discussed in Harden-Davies, ${ }^{38}$ this reveals several common themes that can be summarized as:

- cooperation in scientific research;

- access to the skills and research infrastructure to conduct research;

- standards and methodologies concerning the conduct of research;

- access to the outcomes of scientific research, such as data and samples and scientific knowledge; and

- broader scientific and socioeconomic benefits arising from research.

This highlights several forms of scientific and technological capacity-building that could be pursued under the BвNJ agreement to promote the conservation and sustainable use of marine genetic resources. At the same time, the synergies with broader interpretations of marine technology transfer indicate a need to consider the wider ramifications of benefit-sharing measures for scientific research and technology transfer, and for careful consideration in order to harness opportunities for cooperation and avoid obstacles that could hinder research or counteract efforts to provide a science-basis for the BBNJ agreement. These opportunities and challenges can be explored by considering the existing basis for marine scientific research and the development and transfer of marine technology in UNCLOS.

$36 \quad$ S.A. Laird, C. Monagle and S. Johnston, The Griffith University AstraZeneca Partnership for Natural Product Discovery: An access and benefit-sharing case study (UNU-IAS Report, 2008).

37 Böhm and Collen, n. 35 above.

38 H. Harden-Davies, "Marine science and technology transfer: Can the Intergovernmental Oceanographic Commission advance governance of biodiversity beyond national jurisdiction?," Marine Policy 74 (2016): 260-267. 


\section{The UNCLOS Framework for Scientific and Technological Capacity Building}

This section examines the UNCLOS basis for building scientific and technological capacity, highlighting existing provisions that relate to the two principles for benefit-sharing identified in the PrepCom report. First, ways in which scientific research can be "beneficial to current and future generations" are considered. Second, potential ways to "promote marine scientific research" are considered. It is demonstrated that UNCLOs provides a framework for scientific and technological capacity-building that mirrors benefit-sharing elements identified in the previous section that are centered on a nexus of international science cooperation, access to data, knowledge, information, infrastructure, and training opportunities. Critically, it shows that these are applicable to activities on the high seas as well as the Area.

\section{Beneficial: the Meaning of Research for the Benefit of Mankind}

The importance of science in achieving equitable outcomes is reflected in the Preamble to UnCLOS, which recognizes that the "study, protection and preservation of the marine environment" will contribute to a "just and equitable international economic order." 39 The continuing importance of science and technology transfer to enable developing States to benefit from biodiversity is confirmed in UN Sustainable Development Goal 14.a, which also recognizes the IOC CGTMT in guiding international cooperation in technology transfer. ${ }^{40}$

Participation in scientific research and access to technology and capacitybuilding are key features of benefit-sharing as characterized in the regime of the Area established by UNCLOS Part XI. ${ }^{41}$ Article 140 requires that activities in the Area be carried out for the benefit of mankind as a whole. The International Seabed Authority is to provide for the sharing of financial and other economic benefits in giving effect to the principle of the common heritage of mankind. Similarly, Article 143 requires that scientific research in the Area

39 UNCLOS, n. 3 above, preamble, paras. 3 and 4.

40 UNGA, "Transforming Our World: The 2030 Agenda for Sustainable Development," GA Res 70/1, 7oth Sess., Agenda Items 15 and 116, UN Doc. A/RES/70/1 (25 September 2015), p. 24.

41 J. Brunnée, "Common areas, common heritage, and common concern," in The Oxford Handbook of International Environmental Law, eds., D. Bodansky, J. Brunnée and E. Hey (Oxford University Press, 2008); M. Bourrel, T. Torsten and D. Currie, "The common of heritage of mankind as a means to assess and advance equity in deep sea mining," Marine Policy 95 (2016), <https://doi.org/10.1016/j.marpol.2016.07.017>. 
"shall be carried out for the benefit of mankind as a whole" and explains that this can be achieved as follows:

States Parties shall promote international cooperation in marine scientific research in the Area by: (a) participating in international programmes and encouraging cooperation in marine scientific research by personnel of different countries and of the Authority; (b) ensuring that programmes are developed through the Authority or other international organizations as appropriate for the benefit of developing States and technologically less developed States with a view to: (i) strengthening their research capabilities; (ii) training their personnel and the personnel of the Authority in the techniques and applications of research; (iii) fostering the employment of their qualified personnel in research in the Area; (c) effectively disseminating the results of research and analysis when available, through the Authority or other international channels when appropriate.

In other words, the following elements enable scientific research to "benefit mankind":

- international cooperation in marine scientific research

- enable participation in international scientific programs

- provide opportunities to strengthen research capabilities and train personnel

- disseminate the results of research and analysis

Crucially, these four requirements are not unique to the regime for the Area but also already apply to marine scientific research conducted in ABNJ, including the high seas as described in the following subsection.

\section{Promoting Marine Scientific Research}

The promotion of international cooperation in marine scientific research is addressed in Article 242 of UNCLOS, which indicates that such cooperation should be on the basis of mutual benefit and for peaceful purposes. All States have the right to conduct marine scientific research in the Area and on the high seas (Articles $87(\mathrm{f}), 238,257)$. The freedom to conduct marine scientific research on the high seas (Article $87(\mathrm{f})$ ) is balanced with obligations set out in Part XIII of UNCLOS. ${ }^{42}$ Several such requirements are enshrined in Article 244, concerning publication and dissemination, which provides: 
1. States and competent international organizations shall, in accordance with [UNCLOS] make available by publication and dissemination through appropriate channels information on proposed major programmes and their objectives as well as knowledge resulting from marine scientific research.

2. For this purpose, States, both individually and in cooperation with other States and with competent international organizations, shall actively promote the flow of scientific data and information and the transfer of knowledge resulting from marine scientific research, especially to developing States, as well as the strengthening of the autonomous marine scientific research capabilities of developing States through, inter alia, programmes to provide adequate education and training of their technical and scientific personnel.

This indicates that Article 244 establishes requirements for marine scientific research that could support benefit-sharing in three ways:

- Facilitate international cooperation by making available "information on proposed major programmes";

- Technology transfer by sharing "knowledge resulting from marine scientific research" as well as "scientific data, information and knowledge," which as illustrated above can be considered as a form of technology transfer, and arguably strengthening "the autonomous marine scientific research capabilities"; and

- Capacity-building by strengthening "marine scientific research capabilities," including through education and training.

Taken collectively, these three elements could be considered as interlinked drivers of scientific and technological capacity-building. For example, Part XIV establishes the framework for the development and transfer of marine technology that is inextricably linked to international scientific research cooperation and capacity-building. The objectives of the development and transfer of marine technology (Article 268) and the measures to achieve the objectives (Article 269) place a strong emphasis on international science cooperation to acquire, evaluate, and share data and knowledge as well as to build human, institutional, and technical capacity. ${ }^{43}$ While Part XIV identifies a number of ways to give effect to the development and transfer of marine technology (e.g., access to infrastructure, training opportunities, programs of international science cooperation), it is overall a fairly broad and ambiguous framework. Imbalances in scientific and technical capacity (including institutions, infrastructure, and financial resources) hinder the ability of States to participate in the benefits from scientific research. According to Long, this gap "makes it difficult 
to implement the broader principles of international cooperation and benefitsharing enshrined by the LOSC." ${ }^{44}$ Part XIV is ripe for further implementation.

At the same time, benefit-sharing measures could potentially apply to scientific research, given the lack of a definition of marine scientific research and the resulting blurred distinction with the loosely defined concept of "marine genetic resources activities." Capturing the benefits from scientific research while avoiding unintended consequences of hindering scientific research or stifling innovation is one of the challenges facing States in developing the вв NJ agreement. ${ }^{45}$ One way to avoid such a consequence could be for the Bв NJ agreement to make support for scientific research a priority and provide the enabling mechanisms to enhance it. Such explicit support for science would serve multiple purposes: to enable a science-based approach to conservation and sustainable use, facilitate the acquisition of benefits through access to in-situ genetic resources, and to uphold the requirement under UNCLOS to create favorable conditions for international cooperation in scientific research. Possible ways to promote scientific research are discussed in the next section, alongside options to harness the international nature of scientific research as a vehicle for benefit-sharing through scientific and technological capacity-building.

\section{Specify, Scale-up, and Strengthen Implementation through the B BNJ Agreement}

The preceding analysis demonstrated that scientific and technological capacity provides a focus for benefit-sharing and that existing responsibilities under UNCLOS provide a basis for this aim. An important consideration for the development of the ввNJ agreement is therefore how to give greater effect to existing rights and responsibilities under UNCLOS - meeting obligations relating to the development and transfer of marine technology while also ensuring the promotion of marine scientific research. This section discusses three types of measures that could be adopted through a BBNJ agreement to achieve the objectives of benefit-sharing and further implement the principles and duties enshrined in UNCLOS Parts XIII and XIV, drawing inspiration from other international legal instruments. The measures range along a spectrum of

\footnotetext{
44 R. Long, "Marine science capacity building and technology transfer: Rights and duties go hand in hand under the 1982 UNCLOs," in Law, Science and Ocean Management, eds., M.H. Nordquist, R. Long T.H. Heidar and J.N. Moore (Martinus Nijhoff, 2007), 299, 308-309. Neumann et al., n. 28 above.
} 
ambition from specifying existing duties to more elaborate innovations that could complement a BBNJ agreement. Three types of measures are proposed to give greater effect to the duty to cooperate in scientific research and technology transfer in order to enable capacity-building:

1. What to cooperate on: specifying the purpose for cooperation; elaborate guidelines to determine and promote marine scientific research and facilitate access to in-situ genetic resources.

2. How to cooperate: identifying the benefits and creating an enabling environment for facilitating sharing the outcomes of scientific research, including ex-situ genetic resources, data and knowledge, and training opportunities; develop a Global Plan of Action for marine genetic resources of ABNJ.

3. Who to cooperate: identify institutional mechanisms to scale-up cooperation and enable building scientific and institutional capacity.

\section{What to Cooperate on?}

A Purpose for International Cooperation in Science and Technology for Genetic Resources

UNCLOS provides a broad duty for international cooperation in marine scientific research (Article 242) and the development and transfer of marine technology (Articles 270; 276(2); 277(i); and 278). Articulating a specific purpose for international cooperation to build scientific and technological research capacity in relation to marine genetic resources of ABNJ could help to guide international implementation efforts. For example, the ITPGRFA articulates a clear statement of purpose for activities involving genetic resources that includes "discovery, exploration, collection, characterization, analysis and documentation" in Article 5. This is elaborated in Article 7.2 to include building capacity for the conservation and sustainable use of genetic resources; international activities for conservation, evaluation and documentation; sharing, providing access to, and exchanging genetic resources and technology; and institutional arrangements and funding. Thus, the ITPGRFA establishes a foundation for an integrated approach to explore, conserve, and sustainably use genetic resources, calling for cooperation (Article 5.1) and national commitments (Article 7.1) as well as providing guidance on specific issues for cooperation, including surveys, inventories, and collections (Article 6). The вBNJ agreement could similarly specify a purpose for cooperation that encapsulates the overarching objectives and principles for benefit-sharing and identify key priority areas for the acquisition, sharing, and utilization of marine genetic resources of ABNJ. Specific tools could also guide cooperation, such as guidelines, codes of conduct, standards, or statements of principles. 


\section{Guidelines to Promote Marine Scientific Research}

and International Research Cooperation

UNCLOS calls for the creation of favorable conditions for marine scientific research, although a definition of the activity is not provided. A first step could be to provide for the development of guidelines and criteria for marine scientific research, as is envisaged in UNCLOS Article 251. Such guidelines could serve several purposes in the context of the BBNJ agreement, including to frame an understanding about the range of activities considered to involve marine genetic resources in the context of the agreement. This would help establish the extent to which benefit-sharing requirements would apply, or not apply, across the spectrum of research and development processes; from the collection of a sample to the isolation of a molecule to the development of biotechnology. The guidelines could also elaborate the ways that scientific research could be promoted to support capacity-building and technology transfer. Examples include stipulating requirements for information sharing about scientific research activities through a possible clearinghouse mechanism; identifying principles and standards to be used; offering guidance on information sharing concerning data and samples (such as the location and accessibility of data and samples); and emphasizing the role of research collaboration in technology development. Article 248 of UNCLOs, which specifies some information sharing requirements for marine scientific research in areas within national jurisdiction, could provide a useful starting point. The IOC would be an appropriate body to lead the development of such guidelines, as illustrated by the development of the IOC CGTMT in response to UNCLOS Article 271. Broad engagement in developing the guidelines would promote an outcome that is practical and has broad support from those upon which implementation will be largely dependent - individual scientists and the research institutions that support them.

\section{How to Cooperate?}

Identifying Benefits and Sharing Mechanisms

Given the absence of definitions of "benefit," "technology," "science," and "marine scientific research" in UNCLOS, and the potentially broad interpretation of the meaning of terms under UNCLOS, the B BNJ agreement could draw inspiration from other instruments (such as the Nagoya Protocol Annex, PIP Article 6.1, and ITPGRFA Article 13) to elaborate a description of the benefits of marine genetic resources of $A B N J$. Utilizing the generic term "benefit" as in the ITPGRFA, rather than the terms "non-monetary" and "monetary" benefits as in the Nagoya Protocol, could promote a more holistic approach that avoids the potential for non-financial benefits to be perceived as a "runner-up" prize. Some 
consideration should be given to clarifying the link between sharing scientific research outcomes, technology transfer, and benefit-sharing to build a common understanding of the meaning of (and link between) technology transfer and benefit-sharing, as discussed below.

\section{Scaling-up: Guide Implementation with a Global Plan of Action}

A further way to guide benefit-sharing and give greater effect to international cooperation could be the development of a "Global Plan of Action for the Conservation and Sustainable Use of Marine Genetic Resources of ABNJ." A Global Plan of Action could be used to encourage specificity and ambition in policy measures directed towards scientific research and technology transfer. Global plans of action have already been developed for animal genetic resources, ${ }^{46}$ plant genetic resources for food and agriculture, ${ }^{47}$ forestry genetic resources, ${ }^{48}$ and global pandemic influenza. ${ }^{49}$ These plans establish long-term shared goals that galvanize and focus efforts for research, guiding the development of policies, identify strategic priorities, and focus collaboration to share benefits from genetic resources and build scientific and technological capacity for conservation and sustainable use. They also allow some level of flexibility to adapt to future research priorities or technological advancement. Plans generally include four themes: 1) availability and access to information (e.g., surveying and inventorying genetic resources; developing international technical standards); 2) in-situ conservation and ex-situ conservation (e.g., sustaining ex-situ collections); 3) sustainable use (e.g., characterizing, evaluating, and developing collections of genetic resources); and 4) capacity-building (e.g., national programs, networks, information systems, monitoring systems, human resources, public awareness). The development and implementation of such a plan for marine genetic resources of ABNJ could help guide and focus international cooperation in achieving the objectives of benefit-sharing under a BBNJ agreement, including access to genetic resources in-situ and ex-situ, training opportunities, as well as facilitate research for conservation.

46 FAO Commission on Genetic Resources for Food and Agriculture, "Global Plan of Action for Animal Genetic Resources" (FAO, 2007), available online: <http://www.fao.org/3/a -a1404e.pdf>.

FAO Commission on Genetic Resources for Food and Agriculture, "Second Global Plan of Action for Plant Genetic Resources for Food and Agriculture” (FAO, 2011), available online: <http://www.fao.org/docrep/015/i2624e/i2624eoo.pdf >.

48 Forest Genetic Resources Plan, n. 17 above.

49 World Health Organization, "Pandemic Influenza Preparedness Framework" (2011), para. 6.13.1 [PIP Framework]. 
Access to Research Outcomes: Data, Knowledge, and Samples Data are one category of benefits that could be shared under a BвNJ agreement. The BBNJ agreement could either clarify or provide a platform for subsequent clarification on what data is to be shared; how data is to be shared (e.g., principles and guidelines for acquisition, storage and sharing of data); who is required to share data, and with whom; and which mechanism(s) for data sharing should be used (and how they are to be funded). As noted above, UNCLOS Article 244 provides an obligation for States to publish and disseminate knowledge resulting from marine scientific research. Further, the promotion of the "acquisition, evaluation and dissemination of marine technological knowledge" and facilitating "access to information and data" is a basic objective of the development and transfer of technology in UNCLOS Article 268a. The UN Fish Stocks Agreement (UNFSA) provides an example of how an implementing agreement can elaborate the duty under UNCLOS to share information and data. ${ }^{50}$ UNFSA Article 14 emphasizes the importance of cooperation for data specification and the sharing of analytical techniques and methodologies. ${ }^{51}$ It sets standard requirements for the collection and exchange of scientific data (UNFSA Annex I). ${ }^{52}$ The UNFSA and the more recent Arctic Science Cooperation Agreement ${ }^{53}$ also usefully set criteria for sharing data, such as timeliness, completeness, and accuracy. Such criteria could be useful to support benefitsharing under а ввNJ agreement.

One way to facilitate access to genetic resources ex-situ is through facilitated access to samples. Sharing samples is recognized as a form of benefit-sharing and technology transfer under several international legal instruments. For example, the International Agricultural Research Centres (IARCs) of the Consultative Group on International Agricultural Research (CGIAR) have a recognized role to hold genetic resources in trust within the ITPGRFA under Article 15, and to manage and administer collections, receiving policy guidance from

50 Y. Tanaka, A Dual Approach to Ocean Governance: The Cases of Zonal and Integrated Management in International Law of the Sea (Ashgate, 2008), p. 220.

51 United Nations Agreement for the Implementation of the Provisions of the United Nations Convention on the Law of the Sea of 10 December 1982 relating to the Conservation and Management of Straddling Fish Stocks and Highly Migratory Fish Stocks, 4 August 1995, 2167 United Nations Treaty Series 88, art. 14(2).

$5^{2}$ Id., art. 4(1)(b)(c).

53 Arctic Council, Agreement on Enhancing International Arctic Science Cooperation (May 2017). Article $7(2)$, states that parties shall support "full and open access" to scientific metadata, distinguishing between metadata, scientific data, data products, and published results. The Agreement also points to timeliness, and identifies preferable features of data access, including "online" and "free of charge" or "at no more than the cost of reproduction and delivery." 
a governing body. A further example is provided under the PIP Framework, which specifies a role for scientific research institutions as part of the Global Influenza Surveillance and Response System (GISRS), including laboratories and scientific research centers, national centers, and collaborating centers. ${ }^{54}$ Similarly, the ввNJ agreement could recognize the role of collections of marine genetic resources of $\mathrm{ABNJ}$, such as museums and research institutions, as agents of technology transfer and encourage support for their role in benefitsharing. Learning from the experience of such institutions in implementing the Nagoya Protocol could provide important guidance.

\section{Who to Cooperate and How?}

Although several references are made to international cooperation in marine scientific research, including in Articles 242, 243, and 244, there is little in the way of identified implementation mechanisms, such as institutions, information sharing platforms, or communication channels. The same is true in relation to references to international cooperation in the development and transfer of marine technology; for example, UNCLOS Article 270 simply identifies that international cooperation for the development and transfer of marine technology should "facilitate marine scientific research, the transfer of marine technology, particularly in new fields, and appropriate international funding for ocean research and development." Recognizing these ambiguities, the ввNJ agreement could enable strengthened implementation of existing UNCLOS requirements in support of benefit-sharing by identifying roles and responsibilities for intergovernmental institutions, and clarifying what role, if any, for regional and national marine scientific and technological centers.

\section{Identify Roles and Responsibilities for Intergovernmental Institutions}

Although UNCLOS refers to the role of "competent international organizations" in facilitating international scientific and technical cooperation, ${ }^{55}$ it does not specify particular institutions. ${ }^{56}$ It is relevant to note that several other international legal instruments of relevance to this issue do identify particular institutions as having responsibilities; for example, the ITPGRFA allocates responsibilities to the Food and Agriculture Organization of the United Nations

54 PIP Framework, n. 49 above, para. 4.2.

55 See, e.g., UNCLOS, n. 3 above, arts. 242(1), 272, and 278.

56 The International Seabed Authority (ISA) is a notable exception to this; UnCLOs, id., Articles 273 and 274 have a particular focus on the role of the ISA with respect to the development and transfer of marine technology with respect to activities in the Area. 
(FAO) in addition to other specified institutions. The B BNJ agreement could address this gap by designating a specific institution and giving it specific responsibilities to support benefit-sharing. Such an institution, or institutions, could facilitate scientific and technological cooperation and collaboration, including information sharing; provide scientific and technical assistance to conduct technology needs assessments (such assessments could be made available via a clearinghouse); facilitate data sharing; and monitor and evaluate implementation. There are several options for taking on this role and some of the functions could be shared. A range of organizations that could play some role, including but not limited to the IOC, the International Seabed Authority, the FAO or a new international organization or subsidiary body established under the ввNJ agreement. Given the wide reach of activities relating to marine genetic resources of ABNJ, cooperation and coordination between existing institutions (including international organizations and national scientific research organizations such as museums) and any designated or new institution will be crucial. By specifying a coordinating institution or cooperation mechanism for cooperation between international organizations, the в вNJ agreement could enhance the implementation of Article 278, which recognizes the importance of cooperation among international organizations to implement the development and transfer of marine technology. This role could be complemented by other organs of the institutional framework pertaining to the BBNJ agreement, including a governing body, secretariat, advisory body, and focal points at national, regional, and global scales. Thus, this could help clarify the role, if any, of the regional marine scientific and technological research centers that are given such a prominent role as mechanisms for international scientific and technical cooperation in Part XIV. ${ }^{57}$

\section{Conclusion}

This article has examined whether scientific and technological capacitybuilding could serve as a unifying focus for benefit-sharing to achieve the aspirations and tackle the challenges encapsulated in the PrepCom report. Three conclusions can be drawn.

First, there is a precedent for a benefit-sharing approach that is centered on scientific and technological capacity-building to both incentivize and enable conservation and sustainable use of biodiversity. In conceptualizing genetic resources, it is important to recall that the value of genetic material is not 
just economic, but also ecological, environmental, scientific, and social. The link between genetic resources and biodiversity is explicitly recognized in the ITPGRFA, CBD, Nagoya Protocol, and Global Plan of Action for Forest Genetic Resources. For example, international cooperation in research to facilitate access to research equipment and infrastructure, to data and knowledge, and to training opportunities are all relevant forms of technology transfer that could contribute to capacity-building. The examples of the ITPGRFA, PIP Framework, Nagoya Protocol, and CBD illustrate that there is a precedent for benefitsharing approaches to pursue scientific and technological capacity-building with provisions targeted towards international science cooperation, technology transfer, and capacity-building.

Second, a benefit-sharing approach centered on scientific and technological capacity-building would be consistent with existing obligations of UNCLOS. Parts XIII and XIV of UNCLOS already include a number of obligations for international cooperation in marine scientific research, promoting scientific research, sharing the outcomes of research, and building capacity of developing States to participate in scientific research through the development and transfer of marine technology. UNCLOS Article 244 enshrines these collectively and offers a hook for further elaboration through а в BNJ agreement. The right to conduct marine scientific research on the high seas is not absolute, but balanced with these responsibilities. Critically, these three responsibilities have also been recognized by States as the three key ingredients for scientific research in the Area to "benefit mankind as a whole" (UnCLOS Article 143). The pursuit of benefit-sharing through scientific and technological capacitybuilding would be consistent with existing rights and responsibilities under UNCLOS.

Third, the existing UNCLOS provisions relating to scientific research, technology transfer, and capacity-building could be further specified to strengthen implementation and scale-up international cooperation. The international legal instruments considered in this article highlight several ways that existing UNCLOS duties could be given greater effect through a BBNJ agreement, including by identifying institutional arrangements, elaborating requirements, and providing for enabling mechanisms ranging from information exchange platforms to standardized data access to streamlining avenues to request assistance. Three groups of suggestions have been offered to unite these various threads in giving greater effect to existing UNCLOS duties concerning international cooperation in science and technology summarized as follows:

1. What to cooperate on: specify the purpose for cooperation; elaborate guidelines to determine and promote marine scientific research and facilitate access to in-situ genetic resources. 
2. How to cooperate: creating an enabling environment that promotes marine scientific research and capacity-building, providing greater specification to requirements for sharing data, samples and knowledge deriving from scientific research, identifying information sharing mechanisms; guiding implementation with a Global Plan of Action for marine genetic resources of $\mathrm{ABNJ}$.

3. Who to cooperate: identify institutional mechanisms to scale-up cooperation and enable scientific and technological capacity building.

Developing benefit-sharing measures requires a careful balancing act to find a level of specificity that allows sufficient flexibility to benefit from future scientific advances while ensuring the promotion of scientific research and capacity-building. Scientific and technological capacity-building is unlikely to provide an entirely satisfactory solution for all States, especially those for whom monetary benefits are of particular importance. Many questions remain as to how sustained and reliable funding streams could be secured, and what the nature of the relationship between benefit-sharing and the conservation and sustainable use of biodiversity will ultimately be. However, as momentum builds to develop benefit-sharing solutions that will work in practice, scientific and technological capacity-building is clearly emerging as a unifying focus for benefit-sharing by offering a common interest to build global capacity to study, conserve, and sustainably use the marine genetic diversity of ABNJ. Advancing scientific and technological capacity in this way could better enable the international community to achieve the objective to conserve and sustainably use marine biological diversity in this vast area of the global ocean that lies beyond the limits of national jurisdiction, for current and future generations. 